\title{
Interactions between Climate, Socioeconomics, and Land Dynamics in Qinghai Province, China: A LUCD Model-Based Numerical Experiment
}

\author{
Xiangzheng Deng, ${ }^{1,2}$ Jikun Huang, ${ }^{1,2}$ Yingzhi Lin, ${ }^{3}$ and Qingling Shi ${ }^{1,2}$ \\ ${ }^{1}$ Institute of Geographic and Natural Resources Research, Chinese Academy of Sciences, Beijing 100101, China \\ ${ }^{2}$ Center for Chinese Agricultural Policy, Chinese Academy of Sciences, Beijing 100101, China \\ ${ }^{3}$ School of Mathematics and Physics, China University of Geosciences (Wuhan), Wuhan 430074, China \\ Correspondence should be addressed to Xiangzheng Deng; dengxz.ccap@gmail.com
}

Received 29 August 2013; Accepted 20 November 2013

Academic Editor: Burak Güneralp

Copyright (C) 2013 Xiangzheng Deng et al. This is an open access article distributed under the Creative Commons Attribution License, which permits unrestricted use, distribution, and reproduction in any medium, provided the original work is properly cited.

\begin{abstract}
This simulation-based research produces a set of forecast land use data of Qinghai Province, China, applying the land use change dynamics (LUCD) model. The simulation results show that the land use pattern will almost keep being consistent in the period from 2010 to 2050 with that in 2000 in Qinghai Province. Grassland and barren or sparsely vegetated land will cover more than $80 \%$ of the province's total area. The land use change will be inconspicuous in the period from 2010 to 2050 involving only $0.49 \%$ of the province's land. The expansion of urban and built-up land, grassland, and barren or sparsely vegetated land and the area reduction of mixed dryland/irrigated cropland and pasture, water bodies, and snow or ice will dominate land use changes of the case study area. The changes of urban and built-up land and mixed dryland/irrigated cropland and pasture will slow down over time. Meanwhile, the change rates of water bodies, snow and ice, barren or sparsely vegetated land, and grassland will show an inverted U-shaped trajectory. Except for providing underlying surfaces for RCMs for future climate change assessment, this empirical research of regional land use change may enhance the understanding of land surface system dynamics.
\end{abstract}

\section{Introduction}

Land use change and the resulting changes in land surface characteristics are recognized drivers of climate change [13]. The biogeochemical impacts of land use change on the climate through changing atmospheric concentrations of greenhouse gases (GHGs) have been of great concern. For instance, the GHGs from agriculture land uses are estimated to account for $10-20 \%$ of the total global anthropogenic emissions [4]. The gross $\mathrm{CO}_{2}$ emissions from tropical deforestation are roughly equivalent to $40 \%$ of global fossil fuel emissions from 1990 to 2007 [5]. Besides lands under management, natural land cover types such as wetlands and primeval forest are also found to be large sources and sinks of GHGs [6]. Land use change affects climate by not only impacting GHG emissions but also land surface properties. Urban heat island (UHI) is one of the most noticeable effects of land surface property changes on local climate change [7-9]. Land use change may result in changes of thermal properties (albedo, thermal conductivity, and emissivity) and further affect the surface energy budgets as well as atmospheric circulations [10-13]. Consequently, land use data should play a central role in climate change assessment.

While the importance of land use change in climate change modeling has been fully realized, most regional climate models (RCMs) use historical and constant land use data as underlying surface data $[14,15]$. Always, simulation of climate change is implemented by using land use data of one year of history as underlying surfaces which are assumed to be constant throughout the whole simulation. It is reasonable to assume that the underlying surfaces are constant in experiments of separating the effects of other factors on climate 
change from those of land use change. However, for climate change prediction and assessment, the constant underlying surfaces will affect the accuracy of RCMs.

It has been proved that the alteration of underlying surfaces has significant impacts on the simulation results of RCMs. Jacobson and Ten Hoeve [16] analyzed the effects of conversion of all roofs worldwide to white roofs on temperature with a one-way-nested global-regional Gas, Aerosol, Transport, Radiation, General Circulation, Mesoscale, and Ocean Model (GATOR-GCMOM) and found that white roofs cooled population-weighted temperatures by about $0.02 \mathrm{~K}$ but warmed the Earth overall by about $0.07 \mathrm{~K}$. Rozoff et al. [17] estimated the land use impacts on thunderstorms and found that urban expansion and its initiated UHI played the largest role in initiating deep, moist convection downwind of the city. Guo et al. [18] numerically investigated the effect of urbanized modification on cloud structure and precipitation distribution by using the fifth-generation Pennsylvania State University-National Center for Atmospheric Research (PSUNCAR) Mesoscale Model (MM5) and found that the peak rainfall located near borderline was $40 \mathrm{~mm}$ for the nonurbanized condition and $65 \mathrm{~mm}$ for the urbanized condition. Trusilova et al. [19] investigated the effects of urban land on the climate in Europe on local and regional scales with a modified land surface scheme. The simulation results showed that the diurnal temperature range in urbanized regions was reduced on average by $1.26 \pm 0.71^{\circ} \mathrm{C}$ in summer and by $0.73 \pm$ $0.54^{\circ} \mathrm{C}$ in winter. All above researches have illustrated that it is essential to alter the underlying surfaces in RCMs to conduct more realistic simulations.

While the historic underlying surfaces for RCMs can be derived from remote-sensing images, ground investigation, and aerial photography, the future land use data can only be obtained through model-based simulation. Accurate simulation of land use change is challenging because of the geographically complex socioeconomic drivers and natural constraints. Overall, simulation models of land use change can be classified into three categories: empirical statistical model, cellular automaton (CA) model, and agent-based model $(\mathrm{ABM})[20]$. The CA model with the superiority of simulation process visualization is widely used in land use change simulation, especially urban expansion [21-23]. The Agent-Based Models of Land Use and Land Cover (ABM/LUCC) model were regarded as the most potential modeling strategies for land use change $[24,25]$, but most of the existing models are not compatible with RCMs. Deng et al. provide a novel framework of land use change dynamics (LUCD) model to introduce parameterized land use data into RCMs. The model consists of three modules, namely, economic module, vegetation change module, and agent-based module, and is extraordinarily capable of simulating the land surface processes and their changing patterns in theory.

This empirical study aims to produce a set of forecast land use data for RCMs applying the LUCD model. Qinghai Province which is located in the northwest of country was chosen as our case study area. The major contribution of this paper is that it provides future underlying surface data for RCMs for Qinghai Province and a demonstration of the LUCD model's application. The predicted land use data of this simulation work can be used for future climate change assessment by altering the underlying surfaces of RCMs. This empirical study illustrates that the LUCD model can be coupled with RCMs by introducing its results into RCMs as underlying surfaces. The case study area and simulation scheme are described in Section 2. The data used in our simulation are also introduced in this section. The results and discussion are provided in Section 3 and concluded in the final section.

\section{Data and Methodology}

2.1. Study Area. Qinghai Province which is located at the northeastern part of the Tibetan Plateau is the origins of the Yellow River, the Yangtze River, and the Lancang River. The province ranging from $89^{\circ} 35^{\prime} \mathrm{E}$ to $103^{\circ} 04^{\prime} \mathrm{E}$ and from $31^{\circ} 40^{\prime} \mathrm{N}$ to $39^{\circ} 19^{\prime} \mathrm{N}$ is a plateau with an average elevation of over $3000 \mathrm{~m}$ (Figure 1). The annual average temperature and precipitation in Qinghai Province range from $-5.7^{\circ} \mathrm{C}$ to $-8.5^{\circ} \mathrm{C}$ and from $50 \mathrm{~mm}$ to $450 \mathrm{~mm}$, respectively. The continental climate with scarce rainfall, high evapotranspiration, and low average temperature makes the ecological environment of the province especially fragile [26]. Due to the important function of water source and ecosystem conservation, Qinghai Province is concerned by the research fields of climate change, land use, and cover change, and ecohydrology. Land use change of historical period in Qinghai Province has been widely studied [27-29]. More than $40 \%$ of the province's land is unsuitable for either farming or grazing. According to the remote sensing data in 2000, grassland and barren or sparsely vegetated land cover $52.91 \%$ and $34.96 \%$ of the province's total land area, respectively (Figure 1).

The implementation of the Great Western Development Strategy in 2000 has undoubtedly accelerated the economic development of Qinghai Province. The imbalanced increase of output value of different industries results in industrial structure changes. The proportions of three major industries changed from $15.2: 41.3: 43.5$ in 2000 to $10.0: 55.1: 34.9$ in 2010 . With the gradual decrease of the proportion of primary industry, the percentage of secondary industry has increased year by year and surpassed that of tertiary industry. This change indicates that there are abundant labors transferred from primary industry to secondary industry. This labor transfer leads to population migration from rural area to cities, which undoubtedly accelerates the urban expansion and cropland abandon.

\subsection{Land Use Change Dynamics Model. The LUCD model} is constituted by three modules, namely, economic module, vegetation change module, and agent-based module. In this study, a computable general equilibrium (CGE) model is used in the economic module to calculate the area demand for all land use types in economic activities maximizing economic utility of land uses (Figure 2). And the dynamics of land use (DLS) model is applied to allocate simulated land use change demand at regional scale to grids $[30,31]$. Land is regarded as one of the three primary factors input in commodity production [32]. The land prices vary along with not only time 


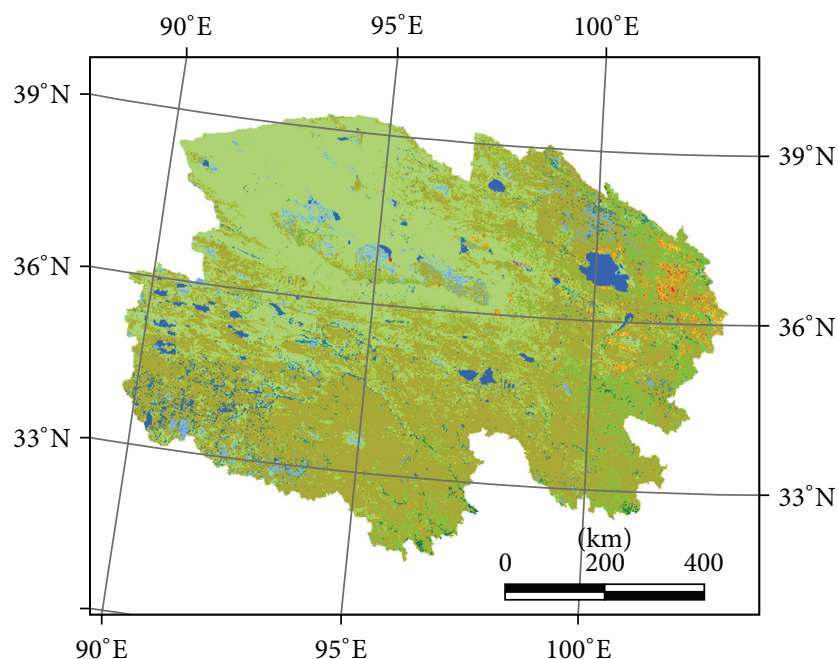

Urban and built-up land

Deciduous needleleaf forest

Dryland cropland and pasture

Mixed dryland/irrigated cropland and pasture

Cropland/grassland mosaic

Evergreen broadleaf forest

Cropland/woodland mosaic

Grassland

Evergreen needleleaf forest

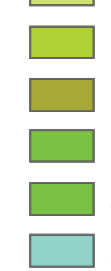

Shrubland

Mixed shrubland/grassland

Mixed forest

Deciduous broadleaf forest

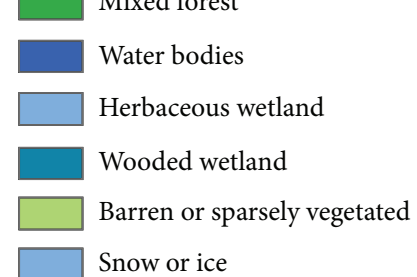

Note. There is no irrigated cropland and pasture, savanna, herbaceous tundra, wooded tundra, mixed tundra, and bare ground tundra in Qinghai Province, China.

FIgURE 1: Location and land uses/cover in Qinghai Province of China in 2000.

but also location and productivity. The land prices are not introduced in the economic module because CGE model does not support a diverse prices modeling framework. Specifically, land uses in economic development in a specific agro-ecological zone (AEZ) are summarized as follows:

$$
\begin{gathered}
Y_{i, e}=b_{i, e} \prod_{h} F_{h, i, e}^{\beta_{h, e}} \prod_{l} A e c_{l, i, e}^{\varsigma_{l, i e}}, \\
A e c_{l, i, e}=\frac{\zeta_{l, i, e} Y_{i, e}}{b_{i, e}}
\end{gathered}
$$

where $Y_{i, e}$ is the value added of the $i$ th firm in the $e$ th AEZ; $A e c_{l, i, e}$ is the input area of the $l$ th land use type in $i$ th firm in the eth AEZ; $F_{h, i, e}$ is the input of the $h$ th factor by the $i$ th firm in the $e$ th AEZ; $b_{i, e}$ is the scaling parameter in production function, also called total factor productivity (TFP); $\zeta_{l, i, e}$ is the share parameter in production functions; and $\beta_{h, i, e}$ is the share parameter in production functions.

The agro-ecological zone (AEZ) model is used in the vegetation change module to assess the growth suitability of specific vegetation and provides the possibility of vegetation change. The AEZ model is developed by Food and Agriculture Organization (FAO) of the United Nations with the collaboration of the International Institute for Applied Systems Analysis (IIASA) [33]. The AEZ model is chosen because it is naturally correlated with AEZs facilitating the coupling of economic module and vegetation change module. Climate, topography, and soil characteristics are three key inputs of the AEZ model. The model can estimate the climate productivity of vegetation driven by climate changes. The possibility of vegetation change can be calculated based on the climate productivity from AEZ model:

$$
P_{v, p, t+1}=\frac{Y_{v, p, t+1}-Y_{v, p, t}}{Y_{v, \max }}
$$

where $P_{v, p, t+1}$ is the possibility of vegetation change of the $v$ th type of vegetation in the pixel $p$ in the $(t+1)$ th year; $Y_{v, p, t}$ is the climate productivity of the $v$ th type of vegetation in the pixel $p$ in the $t$ th year; and $Y_{v, \text { max }}$ is the maximum climate productivity of the $v$ th type of vegetation. A superiority index 


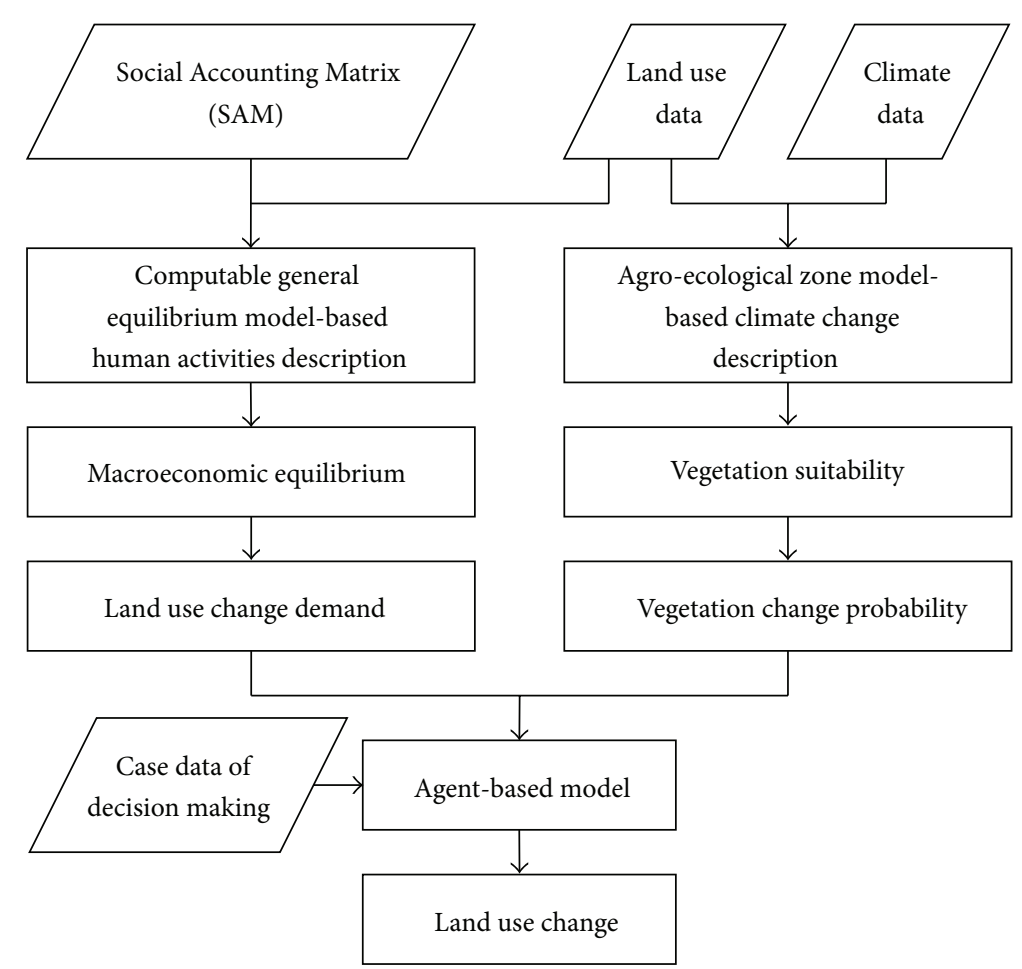

Figure 2: Application framework of land use change dynamics model.

is proposed to compare the superiority of different vegetation in the specific pixel and time:

$$
S_{v, u, p, t+1}=\frac{Y_{v, p, t+1}-Y_{v, p, t}}{Y_{u, p, t+1}-Y_{u, p, t}}
$$

where $S_{v, u, p, t+1}$ is the superiority index of the $v$ th type of vegetation compared with the $u$ th type of vegetation in the pixel $p$ in the $(t+1)$ th year.

The agent-based module identifies if the land use change demand and the possible vegetation change can be realized under the background of irrational decisions [34]. A casebased reasoning (CBR) strategy is used in agent-based module in this study [35]. The dissimilarities between a given household $h$ and all defined household groups in the population can be measured by

$$
D_{h, g}=\sum_{s=1}^{S} w_{s}\left[\frac{\left(V_{h, s}-\bar{V}_{g, s}\right)^{2}}{\left|V_{h, s}+\bar{V}_{g, s}\right|}\right] \text {, }
$$

where $D_{h, g}$ is the distance from household $h(h=1,2, \ldots, H)$ to the household group $g(g=1,2, \ldots, G) ; V_{h, s}$ is the value of variable $s(s=1,2, \ldots, S)$ representing the character of household $h ; \bar{V}_{g, s}$ is the average value of variable $s$ of households in household group $g$; and $w_{s}$ is the weight coefficient of the variable $s$ in explaining the character of household and household group. The household $h$ is assigned into the most similar household group and makes the same land use change decision with the household group:

$$
g^{\prime}=\arg \min \left\{D_{h, 1}, D_{h, 2}, \ldots, D_{h, g}, \ldots, D_{h, G}\right\},
$$

where $g^{\prime}$ is the most similar household group to household $h$. Based on the case database of land use change decision, we can assign each household into one similar household group and deduce its land use decision. For the assessment result of possible vegetation change, the LUCD model provides a criterion to judge which kind of vegetation change will happen in a specific pixel in the agent-based module:

$$
\begin{aligned}
& L_{v, p} \\
& = \begin{cases}1, & \text { if for } \forall u \neq v, P_{v, p, t+1}>0, S_{v, u, p, t+1}>1 \text { or } \leq 0, \\
& \text { or } P_{v, p, t+1} \leq 0, S_{v, u, p, t+1}>0 \text { or } \leq 1, \\
0, & \text { if for } \forall u \neq v, P_{v, p, t+1}>0, S_{v, u, p, t+1}>0 \text { or } \leq 1, \\
& \text { or } P_{v, p, t+1} \leq 0, S_{v, u, p, t+1}>1 \text { or } \leq 0,\end{cases}
\end{aligned}
$$

where $L_{v, p}=1$ denotes that the $v$ th type of vegetation is the dominant vegetation in the pixel $p$ and $L_{v, p}=0$ denotes that the $v$ th type of vegetation is not the dominant vegetation in the pixel $p$. For a specific pixel, vegetation change will happen 
if only the productivity of the one kind of vegetation exceeds that of the original dominant vegetation:

$$
\begin{gathered}
L V_{p, t+1}=v, \quad \text { if for } \forall u \neq v, R Y_{v, p, t+1}>R Y_{u, p, t+1}, \\
R Y_{v, p, t+1}=R Y_{v, p, t}+\frac{R Y_{v, p, t}}{R Y_{p, t}} Y_{v, p, t+1}, \\
R Y_{p, 0}=\sum_{v} \frac{A_{v, p, 0}}{A_{p}} Y_{v, p, 0},
\end{gathered}
$$

where $L V_{p, t+1}$ denotes the new vegetation type that characterized the pixel $p$ in the $(t+1)$ th year; $R Y_{v, p, t+1}$ is the productivity of the $v$ th type of vegetation in the pixel $p$ in the $(t+1)$ th year; $R Y_{p, t}$ is the total productivity of all the vegetation in the pixel $p$ in the $t$ th year; $R Y_{p, 0}$ is the total productivity of all the vegetation in the pixel $p$ in the base year; $A_{p}$ is area of pixel; $A_{v, p, 0}$ is area the $v$ th type of vegetation in the pixel $p$ in the base year; and $Y_{v, p, 0}$ is the productivity of the $v$ th type of vegetation in the pixel $p$ in the base year. The LUCD model, which is spatially explicit, integrates human activities and climate change, rational and irrational decision makings, and macro- and microdynamic models into the land use change.

2.3. Data and Process. The land use data involved in this study was derived from the dataset of the Project of Impacts of Large-Scale Land Use Change on Global Climate, National Basic Research Program of China (973 Program). The dataset is originally established with a $1 \mathrm{~km} \times 1 \mathrm{~km}$ grid scale using the classification system of United States Geological Survey (USGS) based on the interpretation of remotely sensed imagery data and ground survey of 2000 (Figure 1). The data of Social Accounting Matrix (SAM) which is the basis of the economic module of LUCD model is derived from the database of SinoTERM, a multiregional computable general equilibrium (CGE) model of China. The database covers 31 provinces and municipalities including Qinghai Province and extends the published national input-output table of China for 2002 to 137 sectors $[36,37]$. The climate data such as solar radiation, temperature, precipitation, and latent heat flux from 2010 to 2050 are derived from the simulation results of WRF (Weather Research and Forecasting) model. These hourly data of solar radiation, temperature, precipitation, and latent heat flux were reconciled to daily data for the use of AEZ model. The case data of land use decision making which are needed in the agent-based module of LUCD model are derived from the survey data of the Project of Impacts of Large-Scale Land Use Change on Global Climate, 973 Program.

\section{Results and Discussion}

The future land use in Qinghai Province from 2010 to 2050 was obtained by using the LUCD model. The simulation results show that there will be totally eighteen land use types in future in Qinghai Province which remain constant with those in 2000 (Figures 1 and 3). And the land use pattern will almost keep consistent. There will be about $3.54 \times 10^{5}$ hectares of land converted during the period from 2010 to 2050 accounting for $0.49 \%$ of the province's total land area. The expansion of urban and built-up land, grassland, and barren or sparsely vegetated land and the area reduction of mixed dryland/irrigated cropland and pasture, water bodies, and snow or ice will be the dominating of future land use changes of the case study area.

The change of urban and built-up land and mixed dryland/irrigated cropland and pasture will be mainly due to urbanization. The future population migration from rural area to cities will lead to demand increase of urban and builtup land. The expansion of urban and built-up land will seize the areas of other land use types such as dryland cropland and pasture, mixed dryland/irrigated cropland and pasture, grassland, and barren or sparsely vegetated land (Figure 3 ). The simulation results show that the urban and built-up land will expand by $1.12 \times 10^{4}$ hectares with an average annual expansion rate of $0.39 \%$ (Figure 4 ). There will be $3.60 \times 10^{3}$ hectares of barren or sparsely vegetated land converted to urban and built-up land in the period from 2010 to 2050 accounting for $32 \%$ of the new urban and built-up land. As the second largest source of urban and built-up land, grassland will reduce by $2.80 \times 10^{3}$ hectares. And there will be $2.50 \times$ $10^{3}$ hectares of mixed dryland/irrigated cropland and pasture loss due to urban and built-up land expansion. In addition, the rural-urban migration will result in a conversion of $0.30 \times 10^{3}$ hectares from mixed dryland/irrigated cropland and pasture to grassland. Consequently, the area of mixed dryland/irrigated cropland and pasture will reduce by $2.80 \times$ $10^{3}$ hectares (about $0.41 \%$ ) in the period from 2010 to 2050 .

The simulation results show that the change rates of urban and built-up land and mixed dryland/irrigated cropland and pasture will decrease along with time (Figure 4). The urban and built-up land will expand by $4.10 \times 10^{3}$ hectares in the period from 2010 to 2020 and by $3.70 \times 10^{3}$ hectares, $2.00 \times 10^{3}$ hectares, and $1.40 \times 10^{3}$ hectares in the periods of 2020-2030, 2030-2040, and 2040-2050, respectively. The average annual expansion rate will fall from $1.07 \%$ in the period from 2010 to 2020 to $0.18 \%$ in the period from 2040 to 2050 . The mixed dryland/irrigated cropland and pasture will reduce by $1.40 \times$ $10^{3}$ hectares in the period from 2010 to 2020 . This figure will decline to $0.80 \times 10^{3}$ hectares and $0.60 \times 10^{3}$ hectares in the periods of 2020-2030 and 2030-2040, respectively. The area of mixed dryland/irrigated cropland and pasture will stabilize in the period from 2040 to 2050 at $6.81 \times 10^{5}$ hectares.

The global climate change will affect the vegetation pattern through altering temperature, precipitation, solar radiation, and so forth. Future global warming will accelerate the evaporation and lead to shrinkage of water bodies and melt of snow and ice. The simulation results show that the area of water bodies will reduce by $3.17 \times 10^{5}$ hectares and the area covered by snow and ice will reduce by $3.18 \times 10^{4}$ hectares during the period from 2010 to 2050 (Figure 5). Almost all the reduced water bodies and about $54 \%$ of the lost snow and ice covered area are expected to convert to grassland (Figure 3 ). Consequently, the total area of grassland will expand by 3.32 $\times 10^{5}$ hectares (about $0.87 \%$ ) in the period from 2010 to 2050 (Figure 6). The rest of the reduced snow and ice covered land 


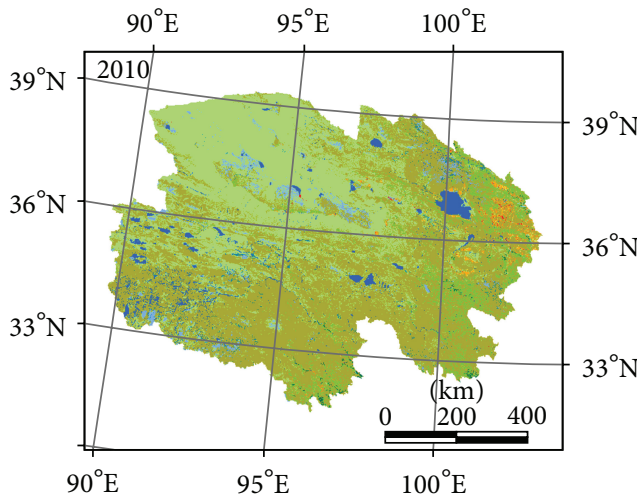

(a)

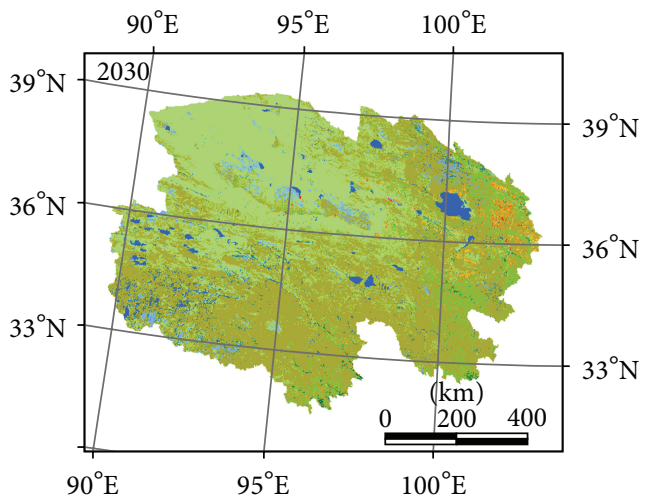

(c)

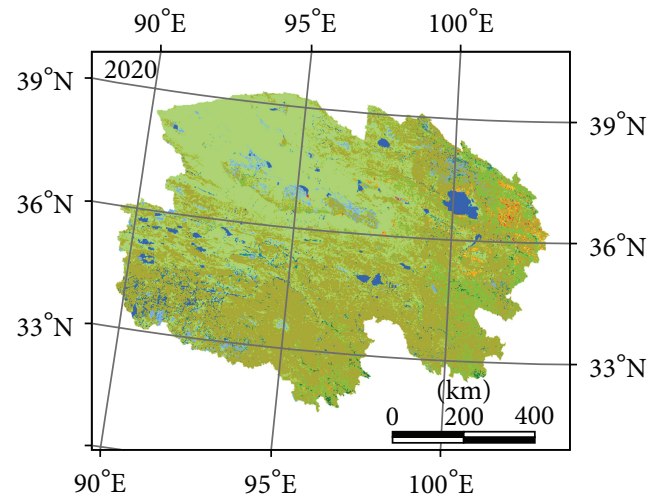

(b)

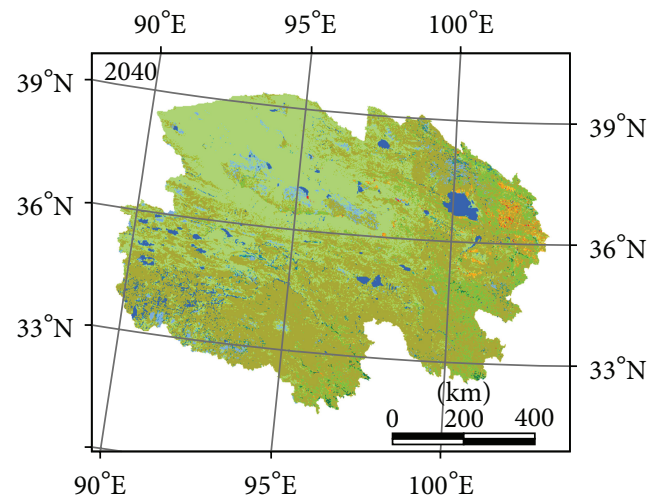

(d)

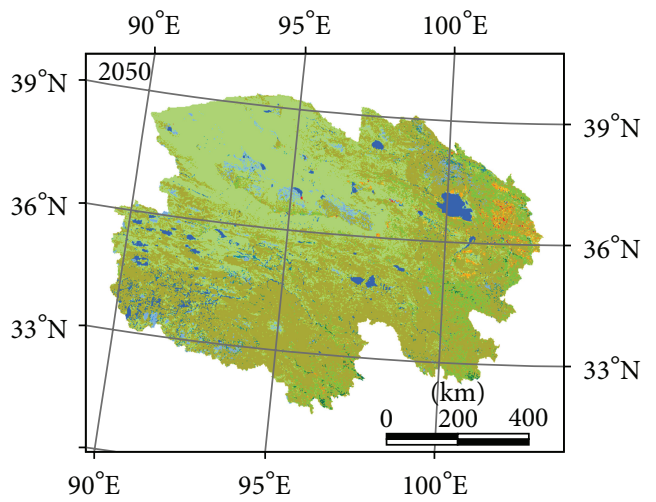

Urban and built-up land

Deciduous needleleaf forest

Dryland cropland and pasture

Mixed dryland/irrigated cropland and pasture

Cropland/grassland mosaic

Evergreen broadleaf forest

Evergreen needleleaf forest

Cropland/woodland mosaic

Mixed forest

Grassland

Shrubland

Mixed shrubland/grassland

Deciduous broadleaf forest

Water bodies

Herbaceous wetland

Wooded wetland

Barren or sparsely vegetated

Snow or ice

Note. There is no irrigated cropland and pasture, savanna, herbaceous tundra, wooded tundra, mixed tundra, and bare ground tundra in Qinghai Province, China.

(e)

FIgURE 3: Simulated LUCC in Qinghai Province of China, 2010-2050. 


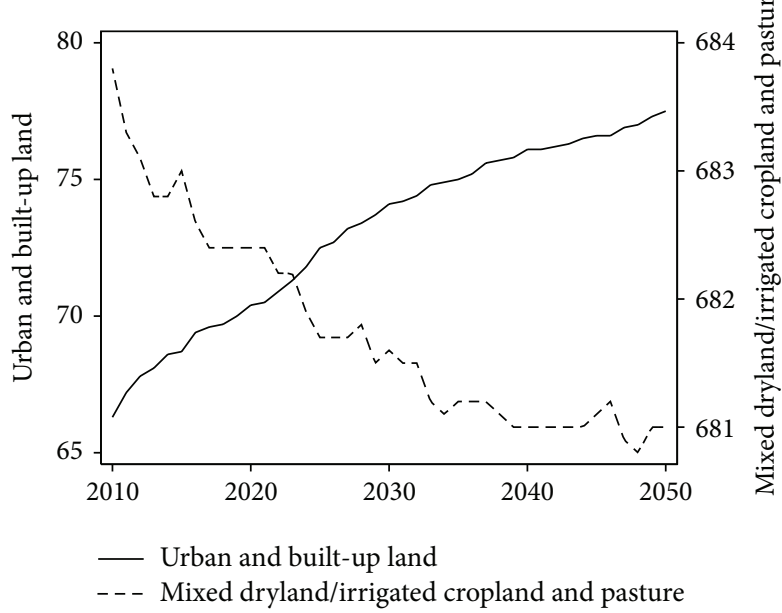

Figure 4: Area changes of urban and built-up land and mixed dryland/irrigated cropland and pasture measured by thousand hectares in Qinghai Province, China.

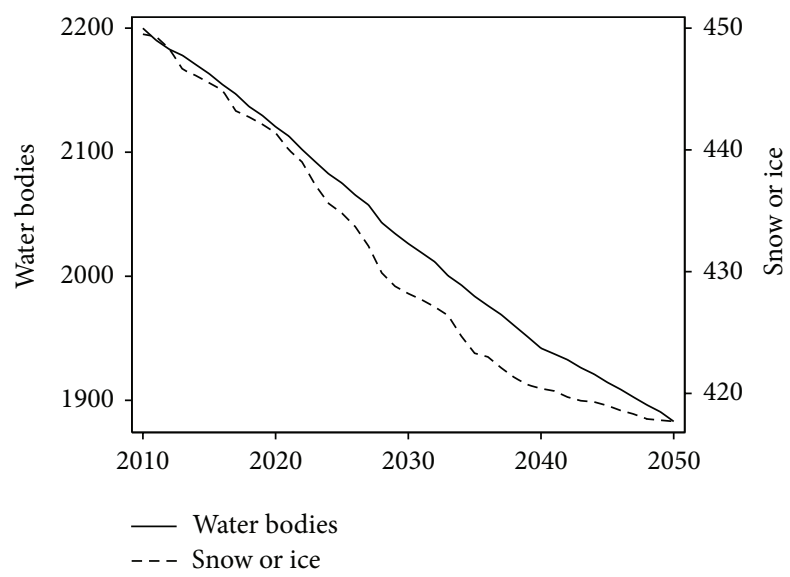

FIgURE 5: Area changes of water bodies and snow or ice measured by thousand hectares in Qinghai Province, China.

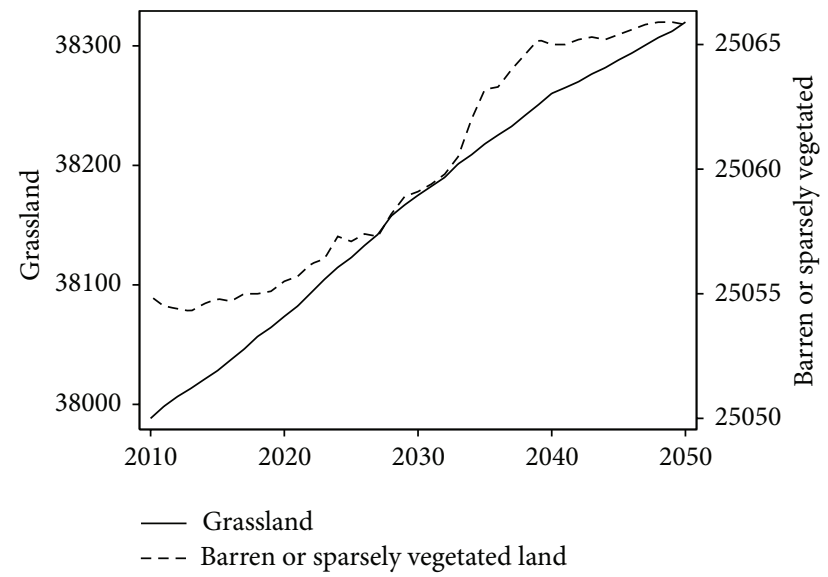

Figure 6: Area changes of grassland and barren or sparsely vegetated land measured by thousand hectares in Qinghai Province, China. $\left(1.45 \times 10^{4}\right.$ hectares $)$ will mainly convert to barren or sparsely vegetated land which will expand by $1.45 \times 10^{4}$ hectares in the period from 2010 to 2050 (Figure 3).

The area of reduced water bodies will be $7.94 \times 10^{4}$ hectares in the period from 2010 to 2020 and climb to 9.42 $\times 10^{4}$ hectares in the period from 2020 to 2030. Then, this figure will turn to decline to $8.43 \times 10^{4}$ hectares in the period from 2030 to 2040 and $5.90 \times 10^{4}$ hectares in the period from 2040 to 2050 . Similarly, the area of reduced snow and ice will reach up to $1.32 \times 10^{4}$ hectares in the period from 2020 to 2030 and finally decline to $0.27 \times 10^{4}$ hectares in the period from 2040 to 2050 . The barren or sparsely vegetated land will totally expand by $0.14 \times 10^{4}$ hectares in the periods $2010-2020$ and 2040-2050 and will expand by $0.36 \times 10^{4}$ hectares and $0.59 \times 10^{4}$ hectares in the period from 2020 to 2030 and the period from 2030 to 2040 , respectively. The area of grassland will expand by $8.53 \times 10^{4}$ hectares in the periods from 2010 to 2020 . This figure will reach up to $10.14 \times 10^{4}$ hectares in the periods from 2020 to 2030 and then decline to $5.97 \times 10^{4}$ hectares in the periods from 2040 to 2050.

The simulation results of LUCD model are in accordance with the existing researches. Unlike the existing researches, the simulation results of this research can be used as the underlying surfaces of RCMs. This benefits from the modeling framework of LUCD model which is compatible with RCMs. By introducing the simulation results of this study in RCMs, the accuracy of climate change assessment can be improved. This empirical research may also enhance the understanding of land surface system dynamics by integrating human activities and climate change, rational and irrational decision makings, and macro- and microdynamic models into land use change.

\section{Conclusions}

A simulation-based research on land use change was implemented. Qinghai Province was selected as case study area due to its importance of water source and ecosystem conservation for China as well as global climate change and land use and land cover change researches for the world. One contribution of this research is the application of the LUCD model which is designed to be compatible with RCMs. This makes it possible to introduce the simulated future land use data into RCMs as underlying surface data. In addition, the land use data provided by this research can inform decision making because the simulation was implemented by taking both human activity and climate change into consideration.

The main conclusions of this work can be summarized as follows.

(1) The land use pattern will keep being consistent in the period from 2010 to 2050 with that in 2000 in Qinghai Province. There will be totally eighteen land use types in future. Grassland and barren or sparsely vegetated land will totally cover more than four-fifths of the province's area. The land use change will be inconspicuous in the period from 2010 to 2050 involving $0.49 \%$ of the province's total land.

(2) The expansion of urban and built-up land, grassland, and barren or sparsely vegetated land, and the area reduction 
of mixed dryland/irrigated cropland and pasture, water bodies, and snow or ice will dominate land use changes of the case study area. The reduction of mixed dryland/irrigated cropland and pasture and urban and built-up land expansion will be mainly due to the future urbanization. The area increase of grassland will mainly come from the shrinkage of water bodies. The changes of urban and built-up land and mixed dryland/irrigated cropland and pasture will slow down over time. Meanwhile, the change rates of water bodies, snow and ice, barren or sparsely vegetated land, and grassland will show an inverted U-shaped trajectory.

(3) This model-based simulation provides underlying surfaces for RCMs for future climate change assessment as well as land use management decision-making information. The empirical research of regional land use change enhances the understanding of land surface system dynamics.

\section{Acknowledgments}

Professor Jiyuan Liu is sincerely acknowledged for his valuable advices for model construction and parameterization. The authors would also like to thank Dr. Burak Güneralp for his advices for improving clarity and expression. This research was supported by China National Natural Science Funds for Distinguished Young Scholar (no. 71225005) and National Key Programme for Developing Basic Science (no. 2012CB955700). Data support from the research projects of the National Natural Science Foundation of China (no. 70503025; no. 70873118; no. 41171434) is also greatly appreciated.

\section{References}

[1] R. A. Pielke Sr., "Land use and climate change," Science, vol. 310, no. 5754, pp. 1625-1626, 2005.

[2] X. Z. Deng, C. H. Zhao, and H. M. Yan, "Systematic modeling of impacts of land use and land cover changes on regional climate: a review," Advances in Meteorology, vol. 2013, Article ID 317678, 11 pages, 2013.

[3] F. Wu, J. Y. Zhan, H. M. Yan, C. C. Shi, and J. Huang, "Land cover mapping based on multisource spatial data mining approach for climate simulation: a case study in the farming-pastoral ecotone of North China," Advances in Meteorology, vol. 2013, Article ID 520803, 12 pages, 2013.

[4] P. H. Verburg, K. Neumann, and L. Nol, "Challenges in using land use and land cover data for global change studies," Global Change Biology, vol. 17, no. 2, pp. 974-989, 2011.

[5] Y. Pan, R. A. Birdsey, J. Fang et al., "A large and persistent carbon sink in the world's forests," Science, vol. 333 , no. 6045, pp. 988993, 2011.

[6] B. Kayranli, M. Scholz, A. Mustafa, and Å. Hedmark, "Carbon storage and fluxes within freshwater wetlands: a critical review," Wetlands, vol. 30, no. 1, pp. 111-124, 2010.

[7] Y. Du, Z. Xie, Y. Zeng, Y. Shi, and J. Wu, "Impact of urban expansion on regional temperature change in the Yangtze River Delta," Journal of Geographical Sciences, vol. 17, no. 4, pp. 387398, 2007.

[8] M. Stathopoulou, A. Synnefa, C. Cartalis, M. Santamouris, T. Karlessi, and H. Akbari, "A surface heat island study of Athens using high-resolution satellite imagery and measurements of the optical and thermal properties of commonly used building and paving materials," International Journal of Sustainable Energy, vol. 28, no. 1-3, pp. 59-76, 2009.

[9] R. J. Qu, X. L. Cui, H. M. Yan, E. J. Ma, and J. Y. Zhan, "Impacts of land cover change on the near-surface temperature in the North China Plain," Advances in Meteorology, vol. 2013, Article ID 409302, 12 pages, 2013.

[10] G. L. Makokha and C. A. Shisanya, “Temperature cooling and warming rates in three different built environments within Nairobi City, Kenya," Advances in Meteorology, vol. 2010, Article ID 686214, 5 pages, 2010.

[11] R. Bornstein and Q. Lin, "Urban heat islands and summertime convective thunderstorms in Atlanta: three case studies," Atmospheric Environment, vol. 34, no. 3, pp. 507-516, 2000.

[12] K. J. Anderson-Teixeira, P. K. Snyder, T. E. Twine, S. V. Cuadra, M. H. Costa, and E. H. Delucia, "Climate-regulation services of natural and agricultural ecoregions of the Americas," Nature Climate Change, vol. 2, no. 3, pp. 177-181, 2012.

[13] E. J. Ma, A. P. Liu, X. Li, F. Wu, and J. Y. Zhan, "Impacts of vegetation change on the regional surface climate: a scenariobased analysis of afforestation in Jiangxi Province, China," Advances in Meteorology, vol. 2013, Article ID 796163, 8 pages, 2013.

[14] Y. Cai, L. Tan, H. Cheng et al., "The variation of summer monsoon precipitation in central China since the last deglaciation," Earth and Planetary Science Letters, vol. 291, no. 1-4, pp. 21-31, 2010.

[15] I. Jankov, W. A. Gallus Jr., M. Segal, B. Shaw, and S. E. Koch, “The impact of different WRF model physical parameterizations and their interactions on warm season MCS rainfall," Weather and Forecasting, vol. 20, no. 6, pp. 1048-1060, 2005.

[16] M. Z. Jacobson and J. E. Ten Hoeve, "Effects of urban surfaces and white roofs on global and regional climate," Journal of Climate, vol. 25, no. 3, pp. 1028-1044, 2012.

[17] C. M. Rozoff, W. R. Cotton, and J. O. Adegoke, "Simulation of St. Louis, Missouri, land use impacts on thunderstorms," Journal of Applied Meteorology, vol. 42, pp. 716-738, 2003.

[18] X. Guo, D. Fu, and J. Wang, "Mesoscale convective precipitation system modified by urbanization in Beijing City," Atmospheric Research, vol. 82, no. 1-2, pp. 112-126, 2006.

[19] K. Trusilova, M. Jung, G. Churkina, U. Karsten, M. Heimann, and M. Claussen, "Urbanization impacts on the climate in Europe: numerical experiments by the PSU-NCAR mesoscale model (MM5)," Journal of Applied Meteorology and Climatology, vol. 47, no. 5, pp. 1442-1455, 2008.

[20] X. Z. Deng, Modeling the Dynamics and Consequences of Land System Change, Springer, 2011.

[21] M. Batty, Y. Xie, and Z. Sun, "Modeling urban dynamics through GIS-based cellular automata," Computers, Environment and Urban Systems, vol. 23, no. 3, pp. 205-233, 1999.

[22] C. A. Jantz and S. J. Goetz, "Analysis of scale dependencies in an urban land-use-change model," International Journal of Geographical Information Science, vol. 19, no. 2, pp. 217-241, 2005.

[23] J. V. Vliet, R. White, and S. Dragicevic, "Modeling urban growth using a variable grid cellular automaton," Computers, Environment and Urban Systems, vol. 33, no. 1, pp. 35-43, 2009.

[24] W. J. McConnell, "Agent-based models of land-use and landcover change," LUCC Report 6, 2001.

[25] T. Zhang, J. Y. Zhan, J. Huang, R. Yu, and C. C. Shi, "An agentbased reasoning of impacts of regional climate changes on land 
use changes in the Three-River Headwaters Region of China," Advances in Meteorology, vol. 2013, Article ID 248194, 9 pages, 2013.

[26] F. Wu, X. Z. Deng, F. Yin, and Y. W. Yuan, "Projected changes of grassland productivity along the Representative Concentration Pathways during 2010-2050 in China," Advances in Meteorology, vol. 2013, Article ID 812723, 9 pages, 2013.

[27] H. Yu, Z. Zhang, and P. Zhang, "RS-and GIS-based evaluation and dynamic monitoring of land desertification in Qinghai Province," Arid Zone Research, vol. 24, no. 2, pp. 153-158, 2007.

[28] Y. Wei, C. Xu, S. Zhang, and L. Song, "Effects of climatic changes on biomass and eco-environments of natural grassland in Haibei region of Qinghai province," Pratacultural Science, vol. 25, no. 2, pp. 12-17, 2008.

[29] L. Wang, Y. Wei, and Z. Niu, "Spatial and temporal variations of vegetation in Qinghai Province based on satellite data," Journal of Geographical Sciences, vol. 18, no. 1, pp. 73-84, 2008.

[30] X. Deng, H. Su, and J. Zhan, "Integration of multiple data sources to simulate the dynamics of land systems," Sensors, vol. 8, no. 2, pp. 620-634, 2008.

[31] X. Deng, J. Huang, Q. Huang, S. Rozelle, and J. Gibson, "Do roads lead to grassland degradation or restoration? a case study in Inner Mongolia, China," Environment and Development Economics, vol. 16, no. 6, pp. 751-773, 2011.

[32] B. Güneralp and K. C. Seto, "Environmental impacts of urban growth from an integrated dynamic perspective: a case study of Shenzhen, South China," Global Environmental Change, vol. 18, no. 4, pp. 720-735, 2008.

[33] J. Schmidhuber and F. N. Tubiello, "Global food security under climate change," Proceedings of the National Academy of Sciences of the United States of America, vol. 104, no. 50, pp. 19703-19708, 2007.

[34] J.-C. Castella, T. N. Trung, and S. Boissau, "Participatory simulation of land-use changes in the northern mountains of Vietnam: the combined use of an agent-based model, a roleplaying game, and a geographic information system," Ecology and Society, vol. 10, no. 1, pp. 1-32, 2005.

[35] R. B. Matthews, N. G. Gilbert, A. Roach, J. G. Polhill, and N. M. Gotts, "Agent-based land-use models: a review of applications," Landscape Ecology, vol. 22, no. 10, pp. 1447-1459, 2007.

[36] M. Horridge and G. Wittwer, "The economic impacts of a construction project, using SinoTERM, a multi-regional CGE model of China," China Economic Review, vol. 19, no. 4, pp. 628634, 2008.

[37] G. Wittwer and M. Horridge, "A multi-regional representation of China's agricultural sectors," China Agricultural Economic Review, vol. 1, no. 4, pp. 420-434, 2009. 

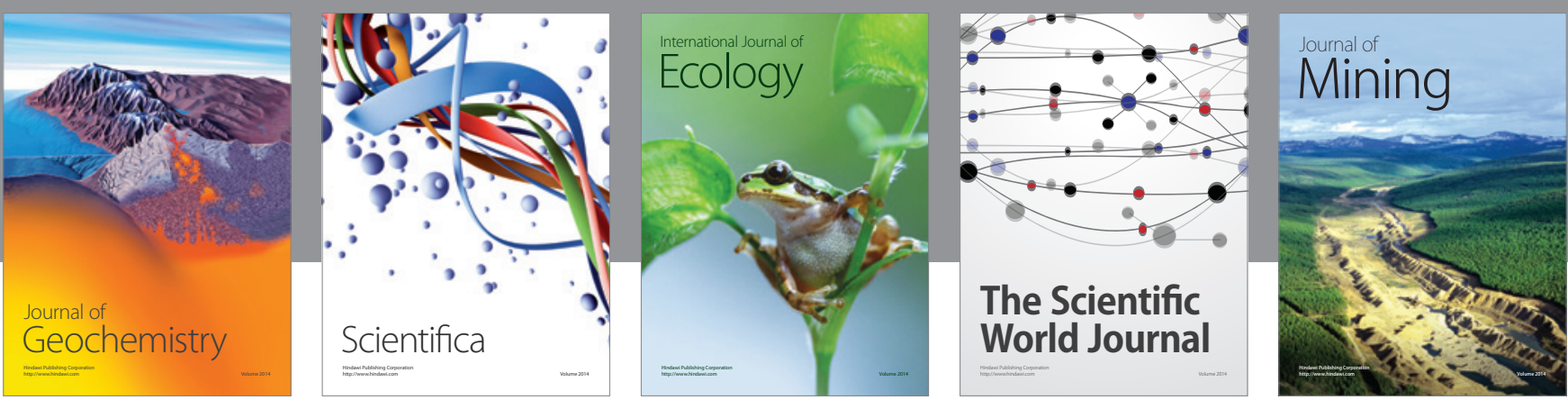

The Scientific World Journal
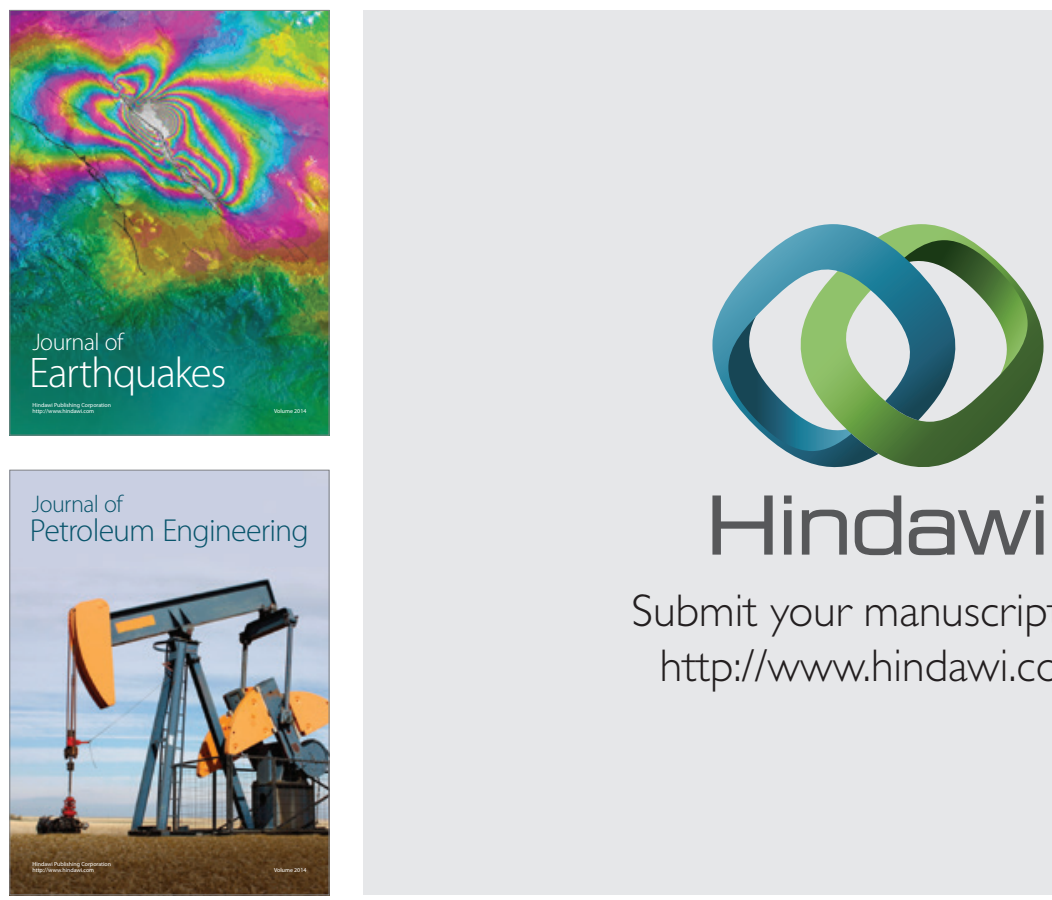

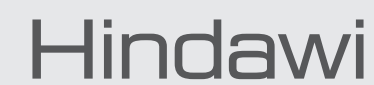

Submit your manuscripts at

http://www.hindawi.com
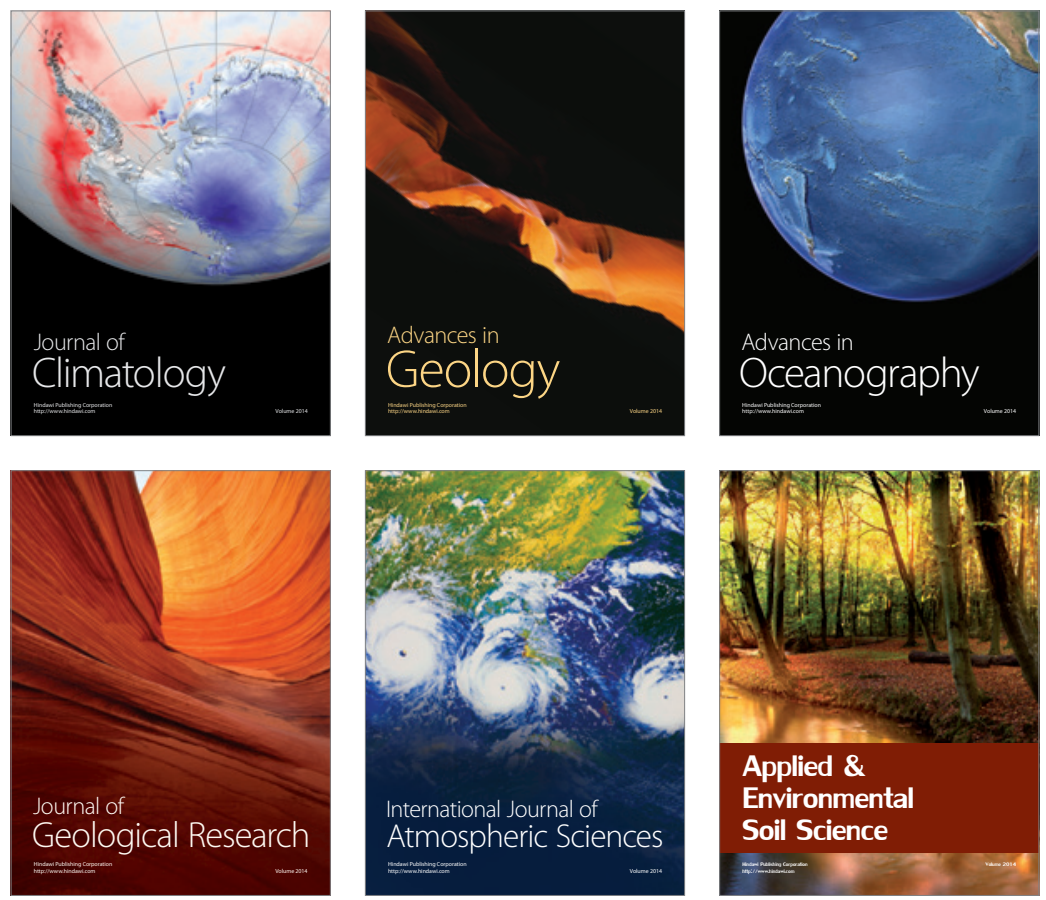
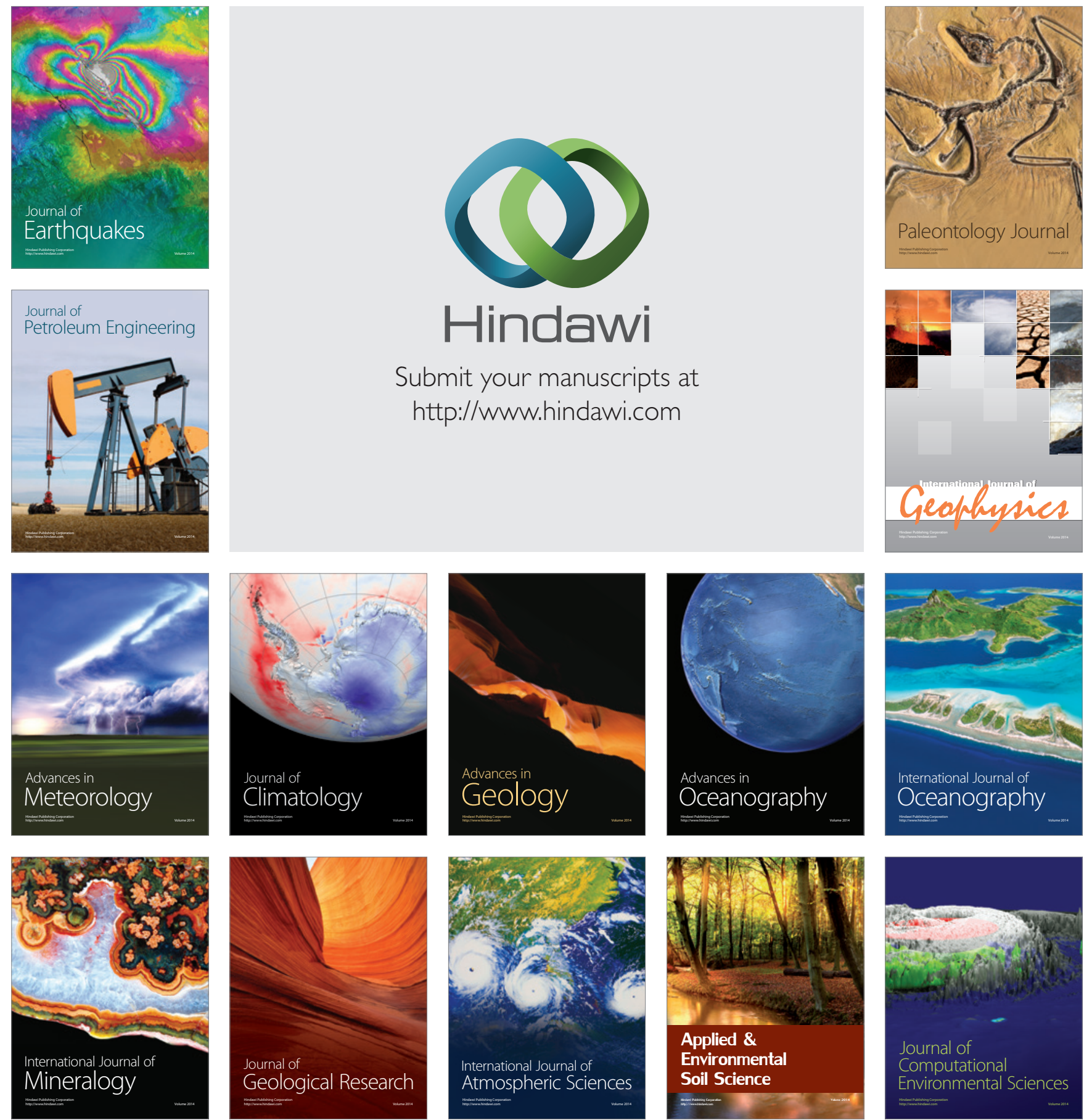